\title{
Neonatal dopamine depletion: Spared and unspared sensorimotor and attentional disorders and effects of further depletion in adulthood
}

\author{
TIMOTHY SCHALLERT \\ University of Texas, Austin, Texas \\ and \\ BRUCE F. PETRIE and IAN Q. WHISHAW \\ University of Lethbridge, Lethbridge, Alberta, Canada
}

\begin{abstract}
Neurological effects of neonatal depletion of dopamine (DA) were examined during adulthood using a comprehensive battery of sensory and motor tests. On Postnatal Day 3, rat pups were pretreated with a noradrenaline uptake inhibitor followed by intraventricular microinfusion of the neurotoxin 6-hydroxydopamine (6-OHDA) to deplete permanently more than $95 \%$ of striatal dopamine content in the medial and lateral caudate in most animals. Control animals received the noradrenaline uptake inhibitor followed by intraventricular infusions of vehicle only. It was confirmed that the sensory and motor behaviors of the neonatal dopamine-depleted (N-6-OHDA) animals were surprisingly intact, considering the well-established symptoms of comparable dopamine depletion in adult-operated animals; however, a detailed analysis revealed an array of chronic abnormalities not previously detected. The severity of impairment was linked to the degree of dopamine deficiency. A group of N-6-OHDA animals (during adulthood) were given an additional, but unilateral, infusion of 6-OHDA into the nigrostriatal tract to further deplete DA in one hemisphere. This treatment caused severe behavioral asymmetries to emerge which were comparable to those observed following the same treatment in control adults. The unusually small level of undepleted DA in the N-6-OHDA animals may have been sufficient to permit sparing of certain functions. Nevertheless, in most behavioral tests, the rats that were most extremely depleted by the neonatal surgery were highly resistant to the additional DA depletion. Thus, neonatal damage may impart unique neural changes in both DAergic and non-DAergic systems that are associated with spared functions. The data may have implications for developmental investigations of recovery and sparing of function, of Parkinson's disease, and of attentional disorders.
\end{abstract}

Permanent depletion of striatal dopamine (DA) can be achieved by intraventricular infusion of 6-hydroxydopamine (6-OHDA) into neonatal rats (Day 3) pretreated with a noradrenergic uptake inhibitor. The depletion can be nearly total, yet remarkably few behavioral deficits have been reported. Thus, adult-operated rats following intraventricular 6-OHDA infusion show aphagia, adipsia, akinesia, and orientation impairments (Marshall, Richardson, \& Teitelbaum, 1974; Schallert, 1988; Schallert, DeRyck, Whishaw, Ramirez, \& Teitelbaum, 1979; Schallert et al., 1982; Schallert, Whishaw, Ramirez, \& Teitelbaum, 1978; Schallert \& Wilcox, 1985; Ungerstedt, 1971; Whishaw, Robinson, Schallert, DeRyck, \& Ramirez, 1978; Zigmond \& Stricker, 1973), whereas neonateoperated rats (N-6-OHDA), tested as adults, do not show

This research was supported by NIH Grant NS-23964 to T. Schallert and an NRC grant to I. Q. Whishaw. Address correspondence to Timothy Schallert, Mezes Hall 330, University of Texas, Austin, TX 78712. these dysfunctions despite comparable DA depletion (Bruno, Jackson, Zigmond, \& Stricker, 1987; Bruno, Snyder, \& Stricker, 1984; Lytle, Shoemaker, Cottman, \& Wurtman, 1972; Raskin et al., 1983; Schallert \& Whishaw, 1988; Smith, Cooper, \& Breese, 1973; Weihmuller \& Bruno, 1989; Whishaw, Funk, Hawryluk, \& Karbashewski, 1987; see also Almli \& Fisher, 1977).

Certain impairments, however, seem not to be spared by neonatal lesions. N-6-OHDA rats never respond appropriately to acute glucoprivation or hypovolemia (Bruno, Zigmond, \& Stricker, 1986). Like adult-operated rats (Marshall et al., 1974; Snyder, Stricker, \& Zigmond, 1985), N-6-OHDA rats become extremely lethargic instead of eating or drinking (respectively) to these physiological challenges. They also are permanently impaired in tests of skilled forelimb use, tongue extension, and spatial navigation (Whishaw et al., 1987), which are impaired in adult-operated rats as well (Evenden \& Robbins, 1984; Pisa, 1988; Sabol, Neill, Wages, Church, \& Justice, 
1985; Schultz, 1982; Spirduso et al., 1985; Whishaw \& Dunnett, 1985; Whishaw \& Kolb, 1983; Whishaw, O'Conner, \& Dunnett, 1986).

In the present study, we examined the behavioral responses of N-6-OHDA rats to sensory stimulation in more detail. Because the role of the striatum in somatosensorimotor processing is well established (Berridge, Venier, \& Robinson, 1989; Dunnett, Bjorklund, Stenevi, \& Iversen, 1981; Dunnett \& Iversen, 1981; Dunnett, Whishaw, Rogers, \& Jones, 1987; Marshall et al., 1974; Schallert \& Hall, 1988; Schallert et al., 1982; Schallert, Upchurch, Wilcox, \& Vaughn, 1983; Schneider \& Lidsky, 1987; Ungerstedt, 1971; Whishaw et al., 1978; White, 1986), it seemed possible that a systematic analysis using a battery of traditional and recently developed quantitative behavioral techniques might provide a more complete picture of chronic sensorimotor functioning in these animals.

It has been suggested that non-DA compensatory neural anomalies might mediate some behaviors in N-6OHDA rats (e.g., Bruno et al., 1987; Jackson, Bruno, Stachowiak, \& Zigmond, 1988; Stellar, Waraczynski, \& Bruno, 1988; Takeichi, Kurumiya, Umemoto, \& Olds, 1986; Weihmuller \& Bruno, 1989). The possibility of changes in DAergic function has been posited as well (Breese et al., 1984; Kostrzewa, White, Zadina, \& Kastin, 1989). In a follow-up study, a small group of N-6-OHDA rats were treated, in adulthood, with a unilateral infusion of 6-OHDA into the medial forebrain bundle to deplete striatal dopamine further in one hemisphere. This was done to address whether a non-DA mechanism underlies any of the spared functions and/or whether the small remnant of dopamine in the N-6-OHDA rats may be sufficient for the operation of certain behavioral functions that, in adult-operated animals, would require far more dopamine.

\section{METHOD}

\section{Subjects}

The animals were male and female Long-Evans hooded rats, which were treated with 6-OHDA or sham infusions as neonates and tested as adults. Two litters were culled to 7 pups each on Day 2 after birth and surgery was performed on Day 3 . The pups were raised in plastic tubs containing sawdust bedding until weaning on Day 27, after which they were housed singly in wire mesh cages with unlimited access to lab chow and water. Lights were on between 0800 and $2000 \mathrm{~h}$, and the animals were tested between 0900 and $1100 \mathrm{~h}$ and between 1400 and $1700 \mathrm{~h}$. Room temperature was $21^{\circ}-23^{\circ} \mathrm{C}$. Weight loss was calculated in all 6-OHDA rats by a comparison with controls. Any rat that lost more than $20 \%$ of the average sex-matched control weight was given supplemental feeding of wet mash or the palatable/nutritious "lab chow cookies" described in Schallert (1982).

All animals were handled very gently and extensively every day for 2 months prior to behavioral testing. Every attempt was made to make them as tame as possible. Testing began when they were 120 days of age.

\section{Surgery}

On Postpartum Day 3, the pups were randomly assigned to lesion (N-6-OHDA) or control groups. Thirty minutes following ad- ministration of desmethylimipramine $(25 \mathrm{mg} / \mathrm{kg}$, s.c.), all pups were anesthetized by being placed in a $-5^{\circ} \mathrm{C}$ controlled chamber $15 \mathrm{~min}$ before surgery. Seven pups received an infusion of $5 \mu$ l containing $150 \mu \mathrm{g}$ (free base) of 6-OHDA hydrobromide (Sigma Chemical Co., St. Louis, $\mathrm{MO}$ ) in a solution of $0.9 \%$ saline and $0.1 \%$ ascorbic acid into each lateral ventricle over a 3 -min period. An equivalent volume of vehicle was infused intraventricularly in 7 control pups. The stereotaxic coordinates for the lateral ventricles were $0.5 \mathrm{~mm}$ anterior and $1.1 \mathrm{~mm}$ lateral to bregma, and $2.5 \mathrm{~mm}$ ventral to the surface of the skull.

Two weeks after testing in adulthood, 4 N-6-OHDA rats received an intraperitoneal injection of desimipramine $(25 \mathrm{mg} / \mathrm{kg})$ followed by anesthetization ( $40-50 \mathrm{mg} / \mathrm{kg}$ pentobarbital) and a unilateral infusion of 6-OHDA into the medial forebrain bundle in an attempt to further deplete dopamine in one hemisphere. The 6-OHDA was delivered via a 26-ga cannula at a concentration of $6 \mu \mathrm{g} / \mu \mathrm{l}$, a volume of $2 \mu \mathrm{l}$, and a rate of $1 \mu \mathrm{l}$ per minute. The stereotaxic coordinates were $3.2 \mathrm{~mm}$ posterior and $1.5 \mathrm{~mm}$ lateral to bregma, and $7.2 \mathrm{~mm}$ ventral to the dura. These same rats also received a sham cannula insertion into the medial forebrain bundle in the hemisphere opposite the side of the 6-OHDA infusion to control for potential behavioral asymmetry-inducing effects caused by nonspecific damage to cortical or other overlying structures (Schallert \& Hall, 1988; Schallert \& Wilcox, 1985).

\section{Behavioral Tests}

Tonic forelimb stimulation. These tests were conducted in the home cage so that the animal would not be distracted. On two separate trials, an adhesive-backed circular piece of paper (Avery; $113 \mathrm{~mm}^{2}$ ) was placed on the distal-radial aspect of the wrist of the left or right forelimb (Barth \& Schallert, 1987; Colle, Holmes, \& Pappius, 1987; Rose, Davey, Love, \& Dell, 1987; Schallert, 1988; Schallert et al., 1982; Schallert et al., 1983; Schallert \& Whishaw, 1984). In half of the rats, the left limb was tested first, and in half the right limb was tested first. On each trial, the rats were removed slowly and gently from their cages for $5-10 \mathrm{sec}$ so that the patch could be firmly attached. The cage was closed quietly and stopwatches were started. In previous work, it was found that the normal response of a rat is to contact the patch by lifting the forelimb to the mouth and to remove the patch by grasping the proximal edge with its teeth and making an upward head movement and a downward forelimb movement to pull it off (Schallert et al., 1982). The animal may contact the patch several times before attempting to remove it. The latency to initially contact the patch with the mouth and the latency to remove it from the limb were recorded. A trial ended when the patch was removed or after $3 \mathrm{~min}$ had elapsed. Other reactions that might distinguish the behaviors of the N-6-OHDA rats from the control rats were recorded as well.

Mild distraction during tonic forelimb stimulation. In this test, responsivity to adhesive patches was assessed either with the home cage closed (normal conditions) or with it partway open (distraction; see also Schallert \& Whishaw, 1984).

Five baseline trials were conducted with the home cage closed. For each rat, adhesive patches were placed on both forelimbs simultaneously. The order of attachment (left vs. right) was randomized. Immediately after the second adhesive patch was attached, the experimenter firmly touched both forelimbs simultaneously. The latency to first contact either of the two patches and the latency to remove them both were recorded. Individual trials were separated by at least $3 \mathrm{~min}$.

Testing was carried out once again, but in an attempt to produce potentially mildly distracting stimulation, each cage was left open about one third of the way out of its rack.

Threshold test. In a threshold test, the size of the patches was reduced to 14.1 or $7.0 \mathrm{~mm}^{2}$. The latencies to contact and to remove the patches were recorded. A trial ended when both patches were removed or when 3 min had elapsed. 
Phasic tactile stimulation and disengagement test. A blunt wooden probe was used to provide light tactual stimulation to the snout, shoulders, or hindquarters (e.g., Hall \& Schallert, 1988; Marshall et al., 1974; Schallert \& Hall, 1988; Schallert \& Whishaw, 1978). Small holes were placed in each solid-metal wall of the cage so that the probe could be inserted into the cage from behind the rat no matter which direction it was facing. To further ensure that the rat did not respond to visual cues, the tests were repeated under dim red light. Stimulus-dependent head and body turning movements were recorded and rated according to a 5-point scale (0-4). A score of 4 was given if the animal turned to bite the probe; a score of 3 was given if the animal turned and contacted the probe with the whiskers or snout; a turn without contact was given a score of 2; an incomplete turn toward the probe was rated as a score of 1 ; and a 0 was assigned if no response was elicited. At least 24 trials per rat were conducted.

In a second orientation test, a piece of chocolate was given to each animal and the latency to orient to the probe during eating behavior was assessed. Schallert and Hall (1988) have shown that adult-operated 6-OHDA rats completely fail to disengage from eating behavior, even after recovery from all orienting deficits. After unilateral intrastriatal 6-OHDA, contralateral orienting is chronically impaired during eating, but not during noneating periods, whereas ipsilateral orienting is vigorous regardless of ongoing behavior (see also Hall \& Schallert, 1988; Mandel, Norrman, Haapaniemi, Brundin, \& Bjorklund, 1989).

Glabellar tap reaction (Meyerson's sign). Like patients with Parkinson's disease (Garland, 1952; Nappi, Sandrini, \& Arrigo, 1985), adult-operated 6-OHDA rats do not stop blinking in response to being tapped on the forehead continuously at a rate of about 2-3 taps/sec (Schallert, Whishaw, \& Teitelbaum, 1978; $n=12$ ). Even after hundreds of repetitive taps, the blinking reaction fails to habituate. In the present experiment, the eraser end of a pencil was used to tap the foreheads (between the eyes) of the neonatal 6-OHDAtreated and control rats. The presence or absence of a blinking response to each of 100 taps was noted.

Bandage-backfall reaction. In the adult-operated animal, and in patients with Parkinson's disease, tonic pressure applied to the head and upper neck muscles via an Ace bandage causes a severe loss of tone to the neck muscles and, if the animal clings or is held while in an upright posture, its head falls backward by its own weight (Teitelbaum, Schallert, \& Whishaw, 1983; Teitelbaum, Wolgin, DeRyck, \& Marin, 1976). A typical control animal maintains the normal posture of the head or vigorously moves its head around. In the present study, neonatal rats were tested for the presence or absence of the bandage-backfall reaction.

Cookie meal initiation. We noticed that when they were given a piece of preferred food, such as a cookie, the N-6-OHDA-treated rats did not eat immediately but instead carried the food around the home cage for what seemed a long time relative to control rats. When they finally did eat, they vigorously consumed the entire piece, as did the controls. To document this further, a $1.0-\mathrm{g}$ piece of familiar chocolate chip cookie was given to each rat. Stopwatches were started when the rats actually picked up the cookie in their mouths. From that point, the latency to begin eating a $10-\mathrm{sec}$ meal was recorded.

Groom latency. Previous work has shown that adult-operated rats with posterolateral hypothalamic lesions (which would have damaged nigrostriatal projections) groom almost immediately in response to a squirt of water on the snout, whereas control rats begin to groom only much later (Robinson \& Whishaw, 1974). In the present study, a 6-cc syringe of water was held $10 \mathrm{~cm}$ from the home cage and discharged through a 26-ga needle onto the snout region of each rat over a period of $30 \mathrm{sec}$. The latency to begin a grooming sequence was recorded. A 60 -sec cutoff was imposed (scored as $60 \mathrm{sec}$ ).

Forelimb motor function. To test forelimb motor coordination, all rats were picked up by the hindquarters and placed in a wheelbarrow-like posture (Schallert et al., 1979) on an extremely narrow (6-mm) beam (Lindner \& Schallert, 1988). As they were pushed forward along the beam with their hindquarters raised, their ability to make accurate stepping movements without dragging their forelimbs, bracing, or making false steps was recorded.

In addition, the posture and use of the forelimbs during spontaneous eating of lab chow was observed (e.g., Kolb, Whishaw, \& Schallert, 1977; Vanderwolf, Kolb, \& Cooley, 1978; Whishaw, Nonneman, \& Kolb, 1981; Whishaw, Schallert, \& Kolb, 1981).

Reaction to handling. All rats were observed for the presence of excessive squealing or jumpiness when picked up and handled. The rats were also placed on a table and the tops of their hindquarters were touched using light pressure applied by the experimenter's hand.

\section{Neurochemical Assay}

The rats were killed by decapitation and their brains were rapidly removed and placed on an ice-cold surface. Immediately, a 6-8-mg punch of tissue was taken from the regions of the left and right dorsolateral caudate, medial caudate, and nucleus accumbens in each brain. All caudate samples were obtained from the rostrocaudal area $\pm 5 \mathrm{~mm}$ from bregma. Lateral caudate samples were centered at the widest lateral convexity of the caudate. Medial caudate samples were from $-2 \mathrm{~mm}$ lateral from the lateral ventricles and dorsal to the level of the medial septum and $2 \mathrm{~mm}$ ventral from the dorsal rim of the caudate. High-performance liquid chromatography (HPLC) with electrochemical detection was used to determine the concentration of DA in the samples (Mefford, 1981).

Samples were analyzed for each hemisphere separately. However, final determination of neonatal DA depletion in each rat was based on mean $\mathrm{ng} / \mathrm{mg}$ wet weight calculated for both hemispheres combined, except for animals with follow-up unilateral 6-OHDA, in which tissue from only the nonadult-lesioned hemisphere was used to estimate the relative severity of the neonatal treatment per se.

\section{Asymmetry Tests (N-6-OHDA Subgroup \\ With Unilateral DA Depletion)}

Several tests were used to determine whether further depletion of DA in one hemisphere during adulthood would yield detectable sensorimotor asymmetries in N-6-OHDA rats.

The first test involved bilateral tonic forelimb stimulation. This test assesses sensory asymmetry independent of postural-motor deficits (Schallert et al., 1982; Schallert et al., 1983). Adhesive patches were attached simultaneously to the radial part of each limb. The animals were returned to the home cage, where the latencies to respond to the ipsilateral versus the contralateral patches were compared.

In the first of two postural-motor tests, the direction of circling behavior was recorded (Schallert et al., 1982). The rats were placed in a circular chamber and the percentage of ipsilateral versus contralateral turns of $360^{\circ}$ was determined in a 5 -min period. The rats were also placed head-down on a grid surface slanted at a $45^{\circ}$ angle. The direction of turning $180^{\circ}$ (ipsilateral or contralateral) to face upward (10 trials) was used to indicate the presence of postural asymmetry.

Orienting reactions to phasic stimulation of the ipsilateral versus the contralateral snout, shoulder, and hindquarter regions were assessed while the animals were in the home cage (Marshall et al., 1974). Phasic perioral stimulation was determined while the animals were engaged in eating a piece of cookie as well as when they were engaged in noneating behavior (Schallert \& Hall, 1988).

\section{RESULTS}

\section{Neurochemistry}

In the analysis of neonatal DA depletion, the data from left and right hemispheres for each region were averaged. 
In rats involved in the follow-up experiment, in which 6-OHDA was infused unilaterally into the nigrostriatal tract during adulthood, only the contralateral hemisphere was used to estimate prelesion neonatal DA depletion. On the basis of HPLC analysis of DA levels, the N-6-OHDA rats were divided into two subgroups: severe (near-total depletion) and moderate. Relative to controls, DA was depleted in the severe subgroup by $96.2 \%(91.1 \%$ 97.8\%) in the medial caudate, $93.5 \%(90 \%-95 \%)$ in the lateral caudate, and $90.7 \%(88.1 \%-92.2 \%)$ in the nucleus accumbens. DA was depleted in the less severe group by $90.8 \%$ in the medial caudate, $65.8 \%$ in the lateral caudate, and $67.4 \%$ in the nucleus accumbens.

In the medial caudate, the mean level of DA in control rats was $12.80 \pm 1.9 \mathrm{ng} / \mathrm{mg}$ wet weight, which was significantly different from that of N-6-OHDA rats $(p<$ .01 ). DA levels in the N-6-OHDA rats were $0.487 \pm$ $.16 \mathrm{ng} / \mathrm{mg}$ (severe subgroup), $1.18 \mathrm{ng} / \mathrm{mg}$ (less severe subgroup), and $0.546 \pm .22 \mathrm{ng} / \mathrm{mg}$ (all N-6-OHDA rats).

In the lateral caudate, the mean level of DA in control rats was $14.50 \pm .61 \mathrm{ng} / \mathrm{mg}$ wet weight, which was significantly different from that of N-6-OHDA rats $(p<$ $.01)$. DA levels in the N-6-OHDA rats were $0.987 \pm .44 \mathrm{ng} / \mathrm{mg}$ (severe subgroup), $5.07 \mathrm{ng} / \mathrm{mg}$ (less severe subgroup), and $2.16 \pm .84 \mathrm{ng} / \mathrm{mg}$ (all N-6-OHDA rats).

In the nucleus accumbens, the mean level of DA in control rats was $10.14 \pm .87 \mathrm{ng} / \mathrm{mg}$ wet weight, which was significantly different from that of N-6-OHDA rats $(p<.01)$. DA levels in the N-6-OHDA DA rats were $0.942 \pm .11 \mathrm{ng} / \mathrm{mg}$ (severe subgroup), $3.31 \mathrm{ng} / \mathrm{mg}$ (less severe subgroup), and $1.62 \pm .53 \mathrm{ng} / \mathrm{mg}$ (all N-6-OHDA rats).

Unilateral follow-up lesion. In the N-6-OHDA rats involved in the follow-up study (i.e., animals that sustained further DA depletion via a unilateral 6-OHDA infusion as adults), the DA-depletion data in the severely depleted rats again were different from those of the less severely depleted animals, particularly in terms of ipsilateralcontralateral asymmetry (see Table 1 ). Relative to controls $(14.50 \mathrm{ng} / \mathrm{mg})$, DA obtained from the dorsal-lateral caudate samples was further depleted in the less severely depleted animals to a level of $94.70 \%$ in the ipsilateral caudate $(0.78 \mathrm{ng} / \mathrm{mg})$, which was much greater than the $60.30 \%$ depletion found in the contralateral caudate $(5.76 \mathrm{ng} / \mathrm{mg})$; however, in the severely depleted rats, mean DA in the ipsilateral caudate was depleted to a level of $94.04 \%(0.873 \mathrm{ng} / \mathrm{mg})$, which was only slightly greater than the $92.53 \%$ depletion found in the contralateral caudate $(1.103 \mathrm{ng} / \mathrm{mg})$.

In the medial caudate, relative to controls $(12.80 \mathrm{ng} /$ $\mathrm{mg}$, DA was depleted in the less severely depleted animals by $94.92 \%$ in the ipsilateral caudate $(0.65 \mathrm{ng} / \mathrm{mg})$, whereas the level of depletion in the contralateral caudate in this subgroup was $86.64 \%(1.71 \mathrm{ng} / \mathrm{mg})$. In the severely depleted rats, DA in the ipsilateral medial caudate was depleted by $97.40 \%(0.333 \mathrm{ng} / \mathrm{mg})$, which was only slightly greater than the $95.56 \%$ depletion found in the contralateral hemisphere $(0.570 \mathrm{ng} / \mathrm{mg})$.
The nucleus accumbens, relative to controls $(10.14$ $\mathrm{ng} / \mathrm{mg}$ ), was depleted of DA in the less severely depleted animals by $81.76 \%$ in the ipsilateral hemisphere ( 1.85 $\mathrm{ng} / \mathrm{mg}$ ), which was much greater than the $53.06 \%$ level of depletion in the contralateral hemisphere $(4.67 \mathrm{ng} / \mathrm{mg})$. In the severe subgroup, the ipsilateral accumbens was depleted by $90.66 \%(0.94 \mathrm{ng} / \mathrm{mg})$, which was virtually unchanged relative to the $90.14 \%(0.99 \mathrm{ng} / \mathrm{mg})$ depletion found in the contralateral accumbens.

\section{Behavioral Tests}

Tonic forelimb stimulation. The control rats contacted and removed the adhesive patches much faster than did the N-6-OHDA rats (see Figure 1). Analysis of variance (ANOVA) indicated that there were significant group effects for contact latency $[F(1,12)=5.44, p<.05]$ and removal latency $[F(1,12)=5.23, p<.05]$. There were large individual differences in sensorimotor behavior that were predictable from the eventual analysis of striatal DA content. Spearman rho correlations performed between the test scores (for contact latency) and dorsolateral caudate DA concentrations were - $.64(p<.02)$. In the severe depletion subgroup the mean latencies to contact and to remove the patches were 35.7 and $91.8 \mathrm{sec}$, respectively. In the less severe subgroup, the mean latencies to contact and to remove the patches were 4.9 and $23.6 \mathrm{sec}$, respectively, which were closer to control values of 5.1 and $10.2 \mathrm{sec}$ (see Figure 1). There was no significant difference between left- and right-limb responses in either group for either contact or removal, so the left and right data were pooled. In addition, there was no correlation between sensory asymmetry (left vs. right bias) and DA asymmetry (left vs. right) in any of the brain regions examined in control or N-6-OHDA rats.

It is important to note that the behavior exhibited by the N-6-OHDA rats in response to the patches was frequently unusual, particularly during these initial trials. Instead of accurately removing the patches with their teeth, some rats often licked the upper part of the appropriate limb at a spot proximal to the location of the patch, only

\section{Response to Tonic Stimulation}

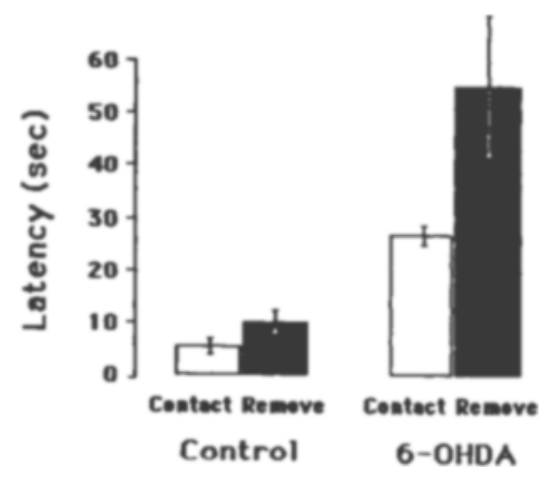

Figure 1. Latency for N-6-OHDA and control rats to contact and to remove adhesive patches from the radial aspect of their forelimbs. 
occasionally contacting the patch itself. Other rats made repeated face-washing or full grooming movements, which resulted in the patch's falling off only incidentally.

Mild distraction test. All rats were affected by mild environmental distraction during sensorimotor testing, but the N-6-OHDA rats were more severely impaired (see Figure 2). Thus, a three-factor ANOVA using the contact and removal data showed not only a significant distraction treatment effect $[F(1,24)=18.04, p<.0001]$, which indicates that all rats were slower to react to the adhesive patches when the cage was left open partway, and a significant group effect $[F(1,24)=23.48, p<$ $.0001]$, which indicates that the N-6-OHDA rats were slower to react than control rats, but also a significant treatment $\times$ groups interaction $[F(1,24)=6.93, p<$ $.01]$, which suggests that the N-6-OHDA rats were more distracted by the open cage than were control animals. In the less severe depletion subgroup, the cage-open latency to initially contact an adhesive patch was much faster $(14.6 \mathrm{sec})$ than in the near-total depletion subgroup (107.2 sec).

Threshold test. The N-6-OHDA-treated rats were severely impaired relative to control rats in reacting to smallsized adhesive stimuli. When the size was reduced to $7 \mathrm{~mm}^{2}$, none of the N-6-OHDA rats responded to them, at least up to the cutoff latency of $4 \mathrm{~min}$. In three cases, the stimuli came off during a grooming sequence, and in one case the stimulus eventually came off during locomotion. In each case, the trial was repeated.

In contrast, all of the control animals contacted and removed the $7-\mathrm{mm}^{2}$ stimuli, albeit more slowly than when they were responding to the standard $113.1-\mathrm{mm}^{2}$ patch (mean $=65.9 \mathrm{sec}$ for contact and $75.5 \mathrm{sec}$ for removal; compare with cage-closed values of control rats depicted in Figure 2, left panel). Note that the control rats' efficiency in removing the $7-\mathrm{mm}^{2}$ patches and their motor persistence were not reduced significantly, as indicated by their near normal latency to remove them once contact was made.

When the size of the patch was $14.1 \mathrm{~mm}^{2}, 3$ of the 7 N-6-OHDA rats failed to respond to it. Of the 4 rats that

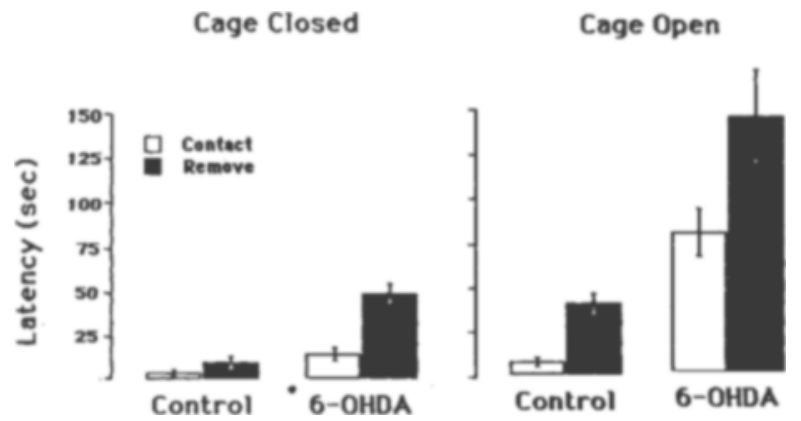

Figure 2. Latency for N-6-OHDA and control rats to contact and to remove adhesive patches from the radial aspect of their forelimbs under two conditions: when the home cage was closed (familiar) and when the home cage was partway open (distraction). did respond, 2 were in the less severe depletion subgroup (mean contact and removal latencies $=13.2$ and $13.4 \mathrm{sec}$, respectively). The other 2 responders, which were in the severe depletion subgroup, contacted the patch in a mean of $104.8 \mathrm{sec}$ and removed it in $120.3 \mathrm{sec}$. One of these severely depleted responders contacted the patch in less than $40 \mathrm{sec}$ and removed it very efficiently (within $1 \mathrm{sec}$ after first contacting it), and this animal was the least depleted of DA in the severe subgroup (89.9\%). In one of the nonresponders, the stimulus came off during a grooming sequence and the trial was repeated.

As expected, all of the control animals contacted and removed the $14.1-\mathrm{mm}^{2}$ stimuli, and did so only slightly more slowly than when they were responding to the standard $113.1-\mathrm{mm}^{2}$ patch (mean $=24.6 \mathrm{sec}$ for contact and $28.6 \mathrm{sec}$ for removal; compare with cage-closed values of control rats depicted in Figure 2, left panel). Note that the control rats' efficiency in removing the $14.1-\mathrm{mm}^{2}$ patches and their motor persistence were not reduced, as indicated by their normal latency to remove them once contact was made.

Phasic tactile stimulation. All rats, including every N-6-OHDA-treated animal, responded to the probe stimulation instantly with vigor and persistence (all rats received the maximum score of 12 for each side of the body on every trial). Even when eating palatable food, all rats disengaged immediately and oriented toward the probe, which is in sharp contrast to the behavior of adult-treated rats (Schallert \& Hall, 1988). If the probe was moved around in the cage, the rats followed it. Orienting was always reliable. It did not matter whether the animal had been sitting quietly for a long period in its cage or whether it had just been handled.

Glabellar tap reaction (Meyerson's sign). All of the N-6-OHDA rats showed the glabellar tap reaction (see Figure 3). To each of 100 taps of the forehead, a blinking response occurred. No habituation was observed, even in the less severe subgroup. However, in the less severe subgroup, many of the blinks seemed to be less complete or more rapid than those of the severe subgroup, and it seemed that on occasional trials, the taps did not cause a blinking response, although high-speed filming would be required to confirm this because the duration of the blink response is so short.

None of the control rats blinked to more than 5 taps (range $=1-5$ taps before habituation). To rule out tactile sensitivity factors, the force of the tap was increased in the control animals; however, a blinking response still did not occur. If the tap occurred at the corner of the eye, the control animals showed a delayed habituation (6-15 taps).

Bandage-backfall reaction. When head-bandaged and held supine without head support (with the head higher than the hindquarters), all of the N-6-OHDA rats showed the bandage-backfall reaction, whereas none of the control rats did. In the near-total subgroup, the head gradually fell back about $45^{\circ}$. In the less severe subgroup, the 
reaction was incomplete; that is, the head did not fall back more than about $10^{\circ}$.

Cookie meal initiation. As shown in Figure 4, the latency to eat a 10-sec meal was much greater in the N-6OHDA group $[t(1,12)=2.88, p<.01]$. Both groups picked up the cookie with their mouths immediately (if anything, the N-6-OHDA rats picked up the cookie a few seconds sooner than did the controls), but rather than settling down to eat the cookie right away, the N-6-OHDA rats carried the food back and forth from one corner of the cage to another. In 3 of the N-6-OHDA rats, there may have occurred a brief (1-2-sec) bout of eating early in the trial, but this was always interrupted by the carrying behavior.

Groom latency. Two trials were run, each on different days. In reaction to having water squirted on their
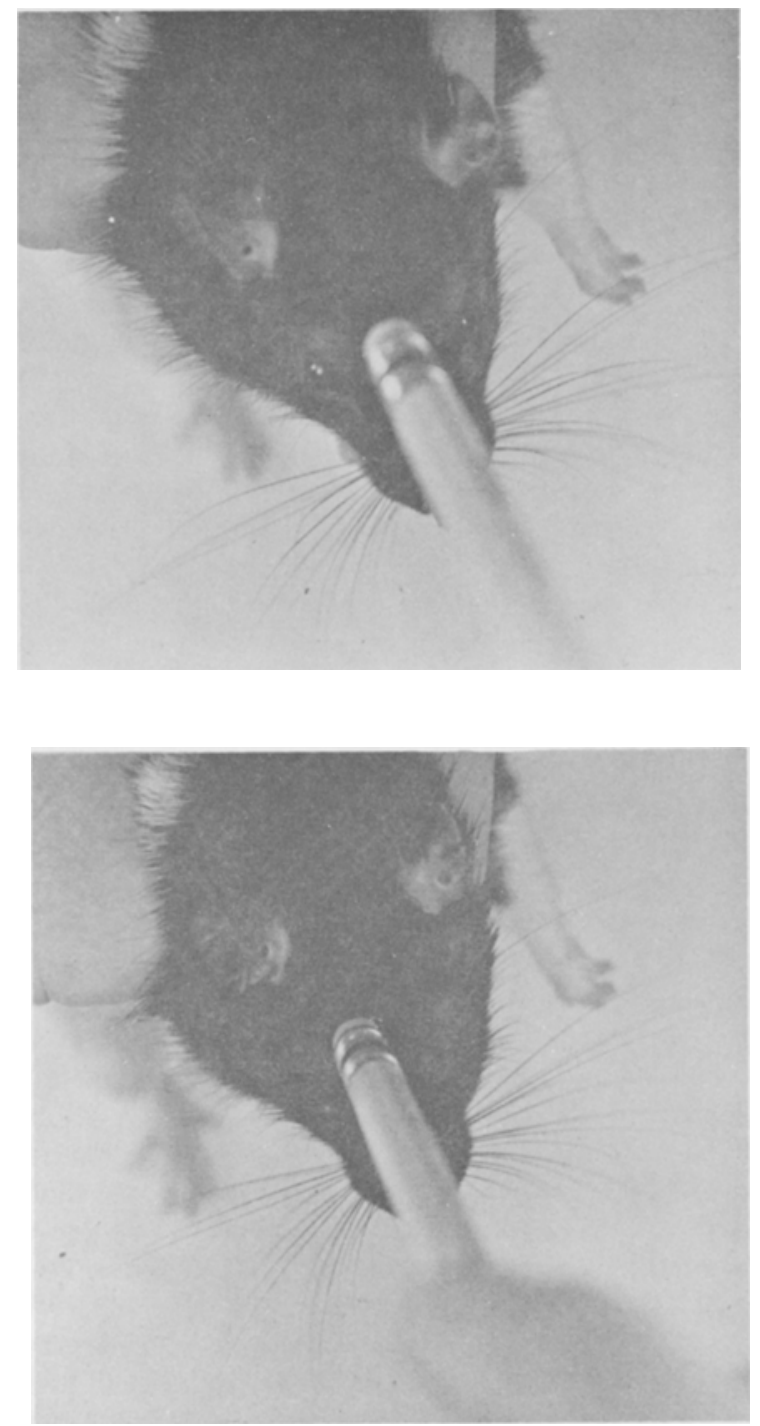

Figure 3. (Top) Control rat does not blink, or rapidly habituates, to 1-Hz light tapping of the forehead (glabellar) area. (Bottom) Neonatal dopamine-depleted animal fails to habituate blinking response to glabellar tapping.

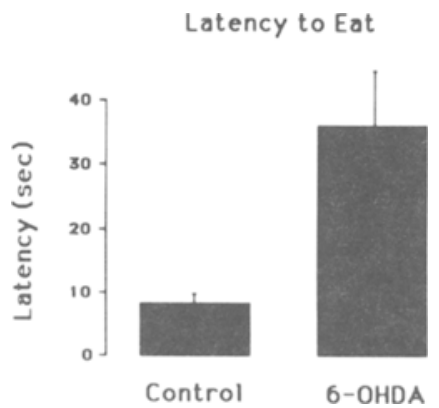

Figure 4. Latency for N-6-OHDA and control rats to initiate eating a piece of cookie after having picked it up with their mouths.

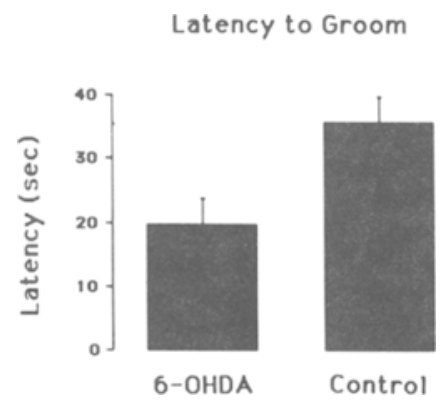

Figure 5. Latency for N-6-OHDA and control rats to initiate a grooming reaction in response to a steady squirt of water onto the snout.

snouts, the N-6-OHDA rats initiated a grooming sequence more quickly than did the control rats (see Figure 5). ANOVA indicated that this difference was statistically reliable $[F(1,12)=6.91, p<.02]$. On the second trial, the latency to respond was reduced in both groups, but nonsignificantly $[F(1,12)=2.44, p<.15]$.

Both groups reacted vigorously by orienting their snouts toward the source of the water stream, much like they did when the wooden probe was rapidly inserted into and out of the cage. As long as the squirting continued, the control rats continued to orient toward it, moving foward to the front of the cage to maintain contact with the steady stream of water. In contrast, the N-6-OHDA rats aborted the orienting reaction and abruptly switched to facewashing followed by a full grooming sequence. The rats in the near-total DA depletion subgroup initiated grooming in $7.7 \mathrm{sec}$ (vs. $43.5 \mathrm{sec}$ for the remaining N-6-OHDA rats). The mean latency for the control animals to initiate a full grooming sequence was $36.8 \mathrm{sec}$, with 2 rats failing to groom within the 60 -sec cutoff. Some of the control rats made one or two brief face-wiping movements; however, even when these movements were scored as the latency to groom, the control animals were slower $(28.2 \mathrm{sec})$.

Forelimb motor function and tongue use. When eating a large pellet of dry lab chow, the N-6-OHDA rats 
Table 1

Effects of Further DA Depletion in N-6-OHDA Rats via Unilateral Infusion of 6-OHDA into Nigrostriatal Tract During Adulthood

\begin{tabular}{|c|c|c|}
\hline \multirow[b]{2}{*}{ Condition } & \multicolumn{2}{|c|}{ Neonatal DA Depletion } \\
\hline & Moderate & Severe \\
\hline \multicolumn{3}{|c|}{ Posture-Independent Sensory Asymmetry } \\
\hline $\begin{array}{l}\text { Prelesion } \\
\text { Postlesion }\end{array}$ & $\begin{array}{l}\text { No Bias } \\
\text { Ipsilateral }\end{array}$ & $\begin{array}{l}\text { No Bias } \\
\text { No Bias }\end{array}$ \\
\hline \multicolumn{3}{|c|}{ Postural/Circling Asymmetry } \\
\hline $\begin{array}{l}\text { Prelesion } \\
\text { Postlesion }\end{array}$ & $\begin{array}{l}\text { No Bias } \\
\text { Ipsilateral }\end{array}$ & $\begin{array}{l}\text { No Bias } \\
\text { No Bias }\end{array}$ \\
\hline \multicolumn{3}{|c|}{ Head Orienting to Phasic Stimulation } \\
\hline $\begin{array}{l}\text { Prelesion } \\
\text { Postlesion }\end{array}$ & $\begin{array}{l}\text { Not Impaired } \\
\text { Neglect Contra }\end{array}$ & $\begin{array}{l}\text { Not Impaired } \\
\text { Slow Contra }\end{array}$ \\
\hline \multicolumn{3}{|c|}{ Disengage Response During Eating } \\
\hline $\begin{array}{l}\text { Prelesion } \\
\text { Postlesion }\end{array}$ & $\begin{array}{l}\text { Not Impaired } \\
\text { Deficit Contra }\end{array}$ & $\begin{array}{l}\text { Not Impaired } \\
\text { Deficit Contra }\end{array}$ \\
\hline \multicolumn{3}{|c|}{ \% DA Depletion (Lateral Caudate) } \\
\hline $\begin{array}{l}\text { Contralateral } \\
\text { Ipsilateral }\end{array}$ & $\begin{array}{l}60.30 \\
94.70\end{array}$ & $\begin{array}{l}92.53 \\
94.04\end{array}$ \\
\hline \multicolumn{3}{|c|}{ \% DA Depletion (Medial Caudate) } \\
\hline $\begin{array}{l}\text { Contralateral } \\
\text { Ipsilateral }\end{array}$ & $\begin{array}{l}86.64 \\
94.92\end{array}$ & $\begin{array}{l}95.56 \\
97.40\end{array}$ \\
\hline \multicolumn{3}{|c|}{ \% DA Depletion (Accumbens) } \\
\hline $\begin{array}{l}\text { Contralateral } \\
\text { Ipsilateral }\end{array}$ & $\begin{array}{l}53.06 \\
81.76\end{array}$ & $\begin{array}{l}90.14 \\
90.66\end{array}$ \\
\hline
\end{tabular}

in the severely DA-depleted group frequently adopted an abnormal limb posture. They failed to pick up the pellet, and instead placed both forelimbs on top of it while eating. The control rats and the rats in the less severely DAdepleted group picked up the pellet and bit off small pieces, which were then eaten while being held by the forepaws. Interestingly, when eating dry cookie pieces of a size equivalent to the small pieces bitten off by the control rats, all animals, including the N-6-OHDA rats, held the food up off the floor using their forelimbs. However, the tongues of the N-6-OHDA rats did not extend as far as those of control rats, which was particularly noticeable during attempts to draw the final small piece (which was too small to hold in the forepaws) into the mouth using the tongue (see also Schallert, 1982).

In the narrow-beam (wheelbarrow) test, the severely DA-depleted rats took a median of 49 trials (range $=$ 5-60) to traverse the beam without errors ( 3 of these rats failed even up to the cutoff of 60 trials), whereas the control rats took a median of 4 trials (range $=1-8$ ) and the less severely N-6-OHDA rats took a median of 6 trials (range $=5-8$ ).

General observations. The fur of the severely DAdepleted rats was not as sleek and well groomed as that of the controls or the less severely DA-depleted rats, and their toenails were frayed or broken. The severely DAdepleted N-6-OHDA rats also were more reactive when handled, as noted in a previous study (Whishaw et al., 1987). Despite daily attempts to calm them down, they failed to habituate, as indicated by chronic vocalization responses to being picked up. When they were touched on the back while standing in an open field, they vocalized and jumped forward. However, if the rats were very slowly picked up, without sudden movements by the experimenter's hand, the animals could be held still for extraordinarily long periods. If, while holding the rat, the experimenter blew gently onto the animal's snout or tapped the snout gently and repeatedly with the eraser end of a pencil, the animal remained immobile with the vibrissae oriented forward.

\section{Behavioral Asymmetry Tests for Follow-Up Unilateral 6-OHDA Lesions}

Table 1 summarizes the effects of adulthood-initiated unilateral 6-OHDA microinfusions into the nigrostriatal projections (a cannula penetration was made in the opposite hemisphere). Prior to unilateral 6-OHDA infusion, no asymmetries were obtained in any of the tests. After surgery, dramatic asymmetries in all sensorimotor tests were found in the less severe subgroup (8-9 days of observation). In contrast, in the severe subgroup, minor or no asymmetries were found, except in the disengage test.

Less severe N-6-OHDA subgroup. In the bilateral stimulation test, the mean postlesion latencies to contact the ipsilateral versus the contralateral stimuli were $3.9 \mathrm{sec}$ versus $43 \mathrm{sec}$ (prelesion latencies were 5.2 and $4.7 \mathrm{sec}$, respectively) and the mean latencies to remove the ipsilateral versus the contralateral stimuli were $5.6 \mathrm{sec}$ versus $43.3 \mathrm{sec}$ (prelesion latencies were 24.5 and $22.8 \mathrm{sec}$, respectively), which represents an ipsilateral bias as typically found in adult-operated rats that have not sustained neonatal DA depletion. In the circling and slanted-grid postural-motor tests, an exclusively ipsilateral bias was observed. In the phasic tactile stimulation test, no contralateral head-turning (orienting) responses could be elicited. Contralateral tactile stimulation frequently elicited movement-freezing reactions or ipsiversive turns; however, during eating, no reaction could be obtained, which indicates the presence of a disengage deficit. Ipsilateral responses were immediate and vigorous on every trial, even during eating behavior.

Severe N-6-OHDA subgroup. The mean latencies to contact the ipsilateral versus the contralateral stimuli were $50.7 \mathrm{sec}$ versus $41.9 \mathrm{sec}$ (prelesion latencies were 35.7 and $34.4 \mathrm{sec}$, respectively) and the mean latencies to remove the ipsilateral versus the contralateral stimuli were $87.6 \mathrm{sec}$ versus $73.2 \mathrm{sec}$ (prelesion latencies were 90.1 and $93.6 \mathrm{sec}$, respectively). In the circling and slantedgrid postural-motor tests, no asymmetries were evident (mean combined percentage of ipsiversive turns in the circular chamber and on the slanted grid $=48.8 \%$ ). In response to phasic tactile stimulation of the contralateral vibrissae, orienting was slower than ipsilateral or control responses for 1-2 days, but was immediate and vigorous on all trials thereafter. In contrast to those observed in the less severe subgroup, contralateral responses to stimulation of more caudal regions of the body (shoulders or hindquarters) were present, but response initiation was 
slower (2-19-sec delay; see Schallert \& Hall, 1988). However, no animal in the severe subgroup responded to contralateral stimulation during eating (disengage deficit).

\section{Weight Loss}

The unilateral 6-OHDA lesion during adulthood significantly affected mean body weight in the N-6-OHDA rats $(p<.01)$. During 8 postoperative days, these animals lost $10.7 \%$ of their prelesion weight (compared with $+2.6 \%$ in control animals and $-0.1 \%$ in the other $\mathrm{N}-6$-OHDA rats). However, no animal was aphagic or adipsic.

\section{DISCUSSION}

Neonatal depletion of DA caused clear sensorimotor abnormalities. Although both casual and quantitative observations of behavior confirmed previous reports that sensory and motor functioning in these rats exceeds that reported in adult-operated animals, nevertheless the range and severity of sensorimotor impairments were considerable.

Compared with control animals, the N-6-OHDA rats (like adult-operated DA-depleted rats or aged unoperated rats; Schallert, 1988; Schallert et al., 1982) were slower to initiate responding to tonic forelimb stimulation. Orientation accuracy and the nature of the movements used to contact and, in particular, to remove the adhesive stimuli were not always normal. For example, a common response was to lick off the stimulus rather than to pull it off using the teeth.

The N-6-OHDA rats were more affected by distracting conditions than were the control animals. When a slight change in the home cage testing environment (cage open slightly) was introduced, the magnitude of the impairment in reactivity to tonic forelimb stimulation was more dramatic in the N-6-OHDA rats. These data are reminiscent of those obtained in rats with cortical damage (Schallert \& Whishaw, 1984), and support the suggestion by Feeser and Raskin (1987) that neonatal DAdepleted rats are more vulnerable to distraction by irrelevant stimuli and are more adversely sensitive to an unfamiliar environment than are control animals.

The animals also showed an increased sensitivity to handling, as indicated by their excessive vocalization and "touchiness" when they were picked up or when they were touched in an unfamiliar environment (Whishaw et al., 1987). Despite repeated attempts to gentle the animals, they never showed habituation. However, this was not a general reaction to touch because the rats did not vocalize or in any way appear to be disturbed (compared with controls) when they were touched or pushed with a wooden probe while in the home cage. Even immediately after being placed in the home cage, reactivity and orienting appeared to be normal. The sensorimotor and locomotor behavior in adult-operated animals with severe DA depletion also are highly susceptible to dis- ruption by slight changes in the living environment (Schallert, 1989). These observations may have implications for theories of striatal function that are based on data obtained from tests conducted outside of the home cage.

Other behaviors also were not spared by the early DA depletion. The N-6-OHDA rats failed to habituate to glabellar tapping. This reaction occurs highly reliably in adult-operated DA-depleted rats (Schallert, Whishaw, \& Teitelbaum, 1978) and in patients with Parkinson's disease (Garland, 1952; Nappi et al., 1985). The N-6-OHDA rats showed the bandage-backfall reaction, which appears in adult DA-deficient rats and in severe cases of Parkinson's disease (Schallert \& Teitelbaum, 1981; Teitelbaum et al., 1983; Teitelbaum et al., 1976; Van Harreveld \& Bogen, 1961).

The N-6-OHDA rats showed enhanced sensitivity to water squirted onto the snout, as do adult-operated animals (Robinson \& Whishaw, 1974). That is, they initiated a grooming reaction sooner than did control animals. They also showed impairment in tongue use (Whishaw et al., 1987; Whishaw et al., 1986; see also Schallert, 1982; Whishaw \& Kolb, 1983) and forelimb functioning during eating of lab chow and in the acquisition of fault-free forelimb stepping in a novel wheelbarrow/beam-walking test.

The reaction of the neonatal DA-depleted rats to a highly palatable dry piece of cookie was interesting. The delay in eating this food was not because they were slower to attend to it. Indeed, they picked up the food slightly more quickly than did the controls. The prolonged foodcarrying reaction observed prior to meal initiation was reminiscent of the reaction in normal rats that have been subjected to a restricted feeding regimen (e.g., Schallert \& Whishaw, 1978), but its duration was exaggerated. It is not known whether adult-operated 6-OHDA animals show this behavior.

It should be emphasized that general locomotion and orienting to phasic stimulation appeared normal even in the most DA-depleted animals. Because adult-operated rats are so obviously debilitated by comparatively severe DA depletion, potential mechanisms for the sparing effect in N-6-OHDA rats have been actively investigated in recent years. The focus has been to search for an anatomical or chemical anomaly in the striatum that is not present in adult-operated rats, but this search has been unsuccessful so far. A robust proliferation of serotonincontaining terminals has been found (Mailman et al., 1983; see also Zhou \& Murphy, 1989). However, this does not appear to mediate the sparing of function, because interfering with serotonergic activity in adulthood does not precipitate dysfunctions that are typically associated with DA deficiency (Bruno et al., 1987; Jackson et al., 1988). Perhaps it will be found that the striatum or related systems in N-6-OHDA rats are characterized by a relative deficiency in some specific neuronal function that normally interacts with the DAergic system in a mutually antagonistic way. There is well-established evidence, for example, that the akinesia observed in adultoperated animals (and in Parkinson's disease) is caused 
in part by a release (disinhibition) of cholinergic activity (see Schallert, Whishaw, Ramirez, \& Teitelbaum, 1978, for review). Moreover, certain postural and lateral headorienting deficits are prevented in adult-operated unilateral 6-OHDA animals by pre-6-OHDA damage to intrinsic cells of the striatum in the same hemisphere (Hall \& Schallert, 1988; see also Schallert et al., 1983). It seems possible that, in contrast to adult-operated rats, neonatally operated rats may be able to lose (or fail to develop properly) forebrain target neurons whose presence in the absence of DA projections could impair function, particularly since early developmental periods are characterized by an extraordinary capacity for compensatory degeneration or pruning mechanisms (e.g., Purves \& Lichtman, 1980).

The follow-up attempt to further deplete DA in some of the N-6-OHDA rats, although preliminary, yielded data that hint at the possible enhanced role of residual DA versus non-DAergic neurons. Unilateral treatment with 6-OHDA in the less severe subgroup yielded dramatic sensorimotor asymmetries in all tests, which suggests that compensatory mechanisms within DAergic projections may mediate spared function in these animals. Unilateral treatment with 6-OHDA in the severely DA-depleted $\mathrm{N}$ 6-OHDA subgroup either precipitated previously unseen sensorimotor asymmetries or was completely noninfluential, depending on the test. Thus, it seems reasonable that both DAergic and non-DAergic compensatory mechanisms may be associated with spared functions when the depletion of DA in neonatal rats is near total. However, the number of animals was minimal, the observations were short-term, and the region/transmitter specificity of the method of unilateral DA depletion has not been confirmed.

We believe that the present investigation may be useful for other reasons. First, the behavioral effects described in the N-6-OHDA rats may temper the impression that early depletion of DA necessarily spares a wide range of sensorimotor functions. A number of chronic abnormalities were found, some novel and some that have been reported in adult-operated animals. Further analyses might well reveal more dysfunctions. Second, the data may bear on hypotheses regarding age-dependent neurological disorders. In an animal analogue of Parkinson's disease, subtotal depletion of DA in young adult rats yields signs of sensorimotor impairment that disappear and later reappear during old age (Schallert, 1983, 1988). It has been suggested that early, perhaps even perinatal, damage to striatal cells, which occurs during intraventricular hemorrhage in people, might be one factor underlying Parkinson's disease. An adequate animal analogue would require a thorough analysis of the chronic sensory and motor effects of neonatal DA depletion. Finally, the N-6-OHDA rat has been used as a model for the attentiondeficit disorder in children (e.g., Raskin et al., 1983), which is thought to be related to striatal dysfunction (Lou, Henriksen, Bruhn, Børner, \& Nielsen, 1989). We have conveyed a broader neurological view of these animals than has previously been depicted and, using a more ex- tensive battery of simple tests, we confirmed a type of enhanced distractibility, habituation impairment, and reactivity that may be relevant to this research area.

\section{REFERENCES}

AlmLI, C. R., \& Fisher, R. S. (1977). Infant rats: Sensorimotor ontogeny and effects of substantia nigra destruction. Brain Research Bulletin, 2, 425-459.

BarTh, T. M., \& Schallert, T. (1987). Somatosensory function of the superior colliculus, somatosensory cortex, and lateral hypothalamus in the rat. Experimental Neurology, 95, 661-678.

Berridge, K. C., Venier, I. L., \& Robinson, T. E. (1989). Taste reactivity analysis of 6-hydroxydopamine-induced aphagia: Implications for arousal and anhedonia hypotheses of dopamine function. Behavioral Neuroscience, 103, 36-45.

Breese, G. R., BAumeister, A. A., McCown, T. J., Emerick, S. G., Frye, G. D., Crotty, K., Mueller, R. A. (1984). Behavioral differences between neonatal and adult 6-hydroxydopamine-treated rats to dopamine agonists: Relevance to neurological symptoms in clinical syndromes with reduced brain dopamine. Journal of Pharmacology \& Experimental Therapeutics, 231, 343-354.

Bruno, J. P., Jackson, D., Zigmond, M. J., \& Stricker, E. M. (1987). Effect of dopamine-depleting brain lesions in rat pups: Role of striatal serotonergic neurons in behavior. Behavioral Neuroscience, 101, 806-811.

Bruno, J. P., SNyder, A. M., \& STRICKER, E. M. (1984). Effect of dopamine-depleting brain lesions on suckling and weaning in rats. Behavioral Neuroscience, 98, 156-161.

Bruno, J. P., Zigmond, M. J., \& Stricker, E. M. (1986). Rats given dopamine depleting brain lesions as neonates do not respond to acute homeostatic imbalances as adults. Behavioral Neuroscience, 100, 125-128.

Colle, L. M., Holmes, L. J., \& Pappius, H. H. (1987). Correlation between behavioral status and cerebral glucose utilization in rats following freezing lesion. Brain Research, 397, 27-36.

Dunnett, S. B., Bjorklund, A., Stenevi, U., \& Iversen, S. D. (1981). Grafts of embryonic substantia nigra reinnervating the ventrolateral striatum ameliorate sensorimotor impairments and akinesia in rats with 6-OHDA lesions of the nigrostriatal pathway. Brain Research, 229, 209-217.

DUNNETT, S. B., IVERSEN, S. D. (1981). Sensorimotor impairments following localized kainic acid and 6-hydroxydopamine lesions of the neostriatum. Brain Research, 248, 121-127.

Dunnet, S. B., Whishaw, I. Q., Rogers, D. C., \& Jones, G. H. (1987). Dopamine-rich grafts ameliorate whole body motor asymmetry and sensory neglect but not independent limb use in rats with 6hydroxydopamine lesions. Brain Research, 415, 63-78.

EvENDEN, J. L., \& RoBbins, T. W. (1984). Effects of unilateral 6hydroxydopamine lesions of the caudate-putamen on skilled forepaw use in the rat. Behavioural Brain Research, 14, 61-68.

Feeser, H. R., Raskin, L. A. (1987). Effects of neonatal dopamine depletion on spatial ability during ontogeny. Behavioral Neuroscience, 101, 812-818.

GaRLAND, H. G. (1952). Parkinsonism. British Medical Journal, i, 153.

HALl, S., SCHAllert, T. (1988). Striatal dopamine and the interface between orienting and ingestive functions. Physiology \& Behavior, 44, 469-471.

Jackson, D., Bruno, J. P., Stachowiak, M. K., \& Zigmond, M. J. (1988). Inhibition of striatal acetylcholine release by serotonin and dopamine after the intracerebral administration of 6-hydroxydopamine to neonatal rats. Brain Research, 457, 267-273.

KolB, B., Whishaw, I. Q., \& Schallert, T. (1977). Aphagia, behavior sequencing and body weight set point following orbital frontal lesions in rats. Physiology \& Behavior, 19, 93-103.

Kostrzewa, R. M., White, T. G., Zadina, J. E., \& Kastin, A. J. (1989). MIF-1 attenuates apomorphine stereotypies in adult rats after neonatal 6-hydroxydopamine. European Journal of Pharmacology, 163, 33-42.

LinDNeR, M. D., \& SChallert, T. (1988). Behavioral effects of 
muscimol-induced prevention of transynaptic degeneration following unilateral ibotenic acid lesions of the caudate nucleus. Society for Neuroscience Abstracts, 14, 718.

lou, H. C., Henriksen, L., Bruhn, P., Børner, H., \& Nielsen, J. B. (1989). Striatal dysfunction in attention deficit and hyperkinetic disorder. Archives of Neurology, 46, 48-52.

Lytle, L. D., Shoemaker, W. J., Cottman, K., \& Wurtman, R. J. (1972). Long-term effects of postnatal 6-hydroxydopamine treatment on tissue catecholamine levels. Journal of Pharmacology \& Experimental Therapeutics, $188,56-64$.

Mailman, R. B., Towle, A., Schulz, D. A., Lewis, M. H., Breese, G. R., DeHaven, D. L., \& KRIGMan, M. R. (1983). Neonatal 6-HDA treatment of rats: Changes in dopamine (DA) receptors, striatal neurochemistry and anatomy. Society for Neuroscience Abstracts, 9, 932.

Mandel, R. J., Norrman, A., Haapaniemi, C., Brundin, P., \& BJORKLUND, A. (1989). Deficits in disengage behavior are not ameliorated by intrastriatal mesencephalic grafts that reverse amphetamineinduced rotational behavior. Society for Neuroscience Abstracts, 15, 1355.

Marshall, J. F., Richardson, J. S., \& Teitelbaum, P. (1974). Nigrostriatal bundle damage and the lateral hypothalamic syndrome. Journal of Comparative Psychology, 87, 808-830.

MefFord, I. N. (1981). Application of high-performance liquid chromatography with electrochemical detection to neurochemical analysis: Measurement of catecholamines, serotonin and metabolites in the rat brain. Journal of Neuroscience Methods, 3, 310-338.

NAPPI, G., SANDRINI, G., ARRIGo, A. (1985). Blink reflex habituation as a tool for clinical and pharmacological research in Parkinson's disease. In P. J. Delwaide \& A. Agnoli (Eds.), Clinical neurophysiology in Parkinsonism (pp. 33-48). New York: Elsevier.

PISA, M. (1988). Motor somatotopy in the striatum in rat: Manipulation, biting, and gait. Behavioural Brain Research, 27, 21-35.

Purves, D., \& Lichtman, J. W. (1980). Elimination of synapses in the developing nervous system. Science, 210, 153-157.

Raskin, L. A., Shaywitz, B. A., Anderson, G. M., Cohen, D. J., TEICHER, M. H., \& LINAKIS, J. (1983). Differential effects of selective dopamine, norepinephrine or catecholamine depletion on activity and learning in the developing rat. Pharmacology, Biochemistry \& Behavior, 19, 743-749.

RoBinson, T. E., Whishaw, 1. Q. (1974). Effects of posterior hypothalamic lesions on voluntary behavior and hippocampal electroencephalograms in the rat. Journal of Comparative \& Physiological Psychology, 86, 768-786

Rose, F. D., Davey, M. J., Love, S., \& Dell, P. A. (1987). Environmental enrichment and recovery from contralateral sensory neglect in rats with large unilateral neocortical lesions. Behavioural Brain Research, 24, 195-202.

Sabol, K. E., Neill, D. B., Wages, S. A., Church, W. H., \& JUSTICE, J. (1985). Dopamine depletion in a striatal subregion disrupts performance of a skilled motor task in the rat. Brain Research, 35, 33-43.

SCHALleRT, T. (1982). Adipsia produced by lateral hypothalamic lesions: Facilitation of recovery by preoperative restriction of water intake. Joumal of Comparative \& Physiological Psychology, 96, 604-614.

SCHALLERT, T. (1983). Sensorimotor impairment and recovery of function in brain-damaged rats: Reappearance of symptoms during old age. Behavioral Neuroscience, 97, 159-164.

SCHALLERT, T. (1988). Aging-dependent emergence of sensorimotor dysfunction in rats recovered from dopamine depletion sustained early in life. In J. A. Joseph (Ed.), Central determinants of age-related decline in motor function (Vol. 515, pp. 108-120). New York: New York Academy of Science.

SchallerT, T. (1989). Preoperative intermittent feeding or drinking regimens enhance postlesion sensorimotor function. In J. Schulkin (Ed.), Preoperative events: Their effects on behavior following brain damage (pp. 1-19). Hillsdale, NJ: Erlbaum.

Schallert, T., DeRyck, M., Whishaw, I. Q., RAmireZ, V. D., \& TeITElbaum, P. (1979). Excessive bracing reactions and their control by atropine and L-dopa in an animal analogue of Parkinsonism. Experimental Neurology, 64, 33-43.
SChallert, T., Hall, S. (1988). "Disengage" sensorimotor deficit following apparent recovery from unilateral dopamine depletion. $B e$ havioural Brain Research, 30, 15-24.

Schallert, T., \& Teitelbaum, P. (1981). Haloperidol, catalepsy, and equilibrating functions in the rat: Antagonistic interaction of clinging and labyrinthine righting reactions. Physiology \& Behavior, 27, 1077-1083.

Schallert, T., Upchurch, M., Lobaugh, N., Farrar, S. B., SpirDuso, W. W., Gilliam, P., Vaughn, D., \& Wilcox, R. E. (1982). Tactile extinction: Distinguishing between sensorimotor and motor asymmetries in rats with unilateral nigrostriatal damage. Pharmacology, Biochemistry \& Behavior, 16, 455-462.

Schallert, T., UPChURCh, M., Wilcox, R. E., \& VAughn, D. M. (1983). Posture-independent sensorimotor analysis of inter-hemispheric receptor asymmetries in neostriatum. Pharmacology, Biochemistry \& Behavior, 18, 753-759.

Schallert, T., Whishaw, I. Q. (1978). Two types of aphagia and two types of sensorimotor impairment after lateral hypothalamic lesions: Observations in normal weight, dieted, and fattened rats. Journal of Comparative \& Physiological Psychology, 92, 720-741.

SCHALleRT, T., \& Whishaw, I. Q. (1984). Bilateral cutaneous stimulation of the somatosensory system in hemidecorticate rats. Behavioral Neuroscience, 98, 518-540.

SCHAllERT, T., \& WhishaW, I. Q. (1988). Spared and unspared sensorimotor functions following neonatal dopamine depletion: Effects of further dopamine depletion in adulthood. International Society for Developmental Psychobiology Abstracts.

Schallert, T., Whishaw, I. Q., Ramirez, V. D., \& Teitelaaum, P. (1978). Compulsive abnormal walking caused by anticholinergics in akinetic, 6-hydroxydopamine-treated rats. Science, 199, 1461-1463.

Schallert, T., Whishaw, I. Q., \& Teitelbaum, P. (1978). Blinking reaction to glabellar tapping fails to habituate in dopamine-deficient rats. Unpublished raw data.

SchallerT, T., \& WILCox, R. E. (1985). Neurotransmitter-selective brain lesions. In A. A. Boulton \& G. B. Baker (Eds.), Neuromethods: Neurochemistry, general techniques (Vol. 1, pp. 343-387). Clifton, NJ: Humana Press.

SCHNEIDER, J. S., \& LIDSKY, T. I. (Eds.) (1987). Basal ganglia and motor behavior: Sensory aspects of motor functions. New York: Hogrofe International.

Schultz, W. (1982). Depletion of dopamine in the striatum as an experimental model of Parkinsonism: Direct effects and adaptive mechanisms. Progress in Neurobiology, 8, 121-166.

Smith, R. D., Cooper, B. R., \& Breese, G. R. (1973). Growth and behavioral changes in developing rats treated intracisternally with 6 hydroxydopamine: Evidence for involvement of brain dopamine. Journal of Pharmacology \& Experimental Therapeutics, 185, 609-619.

SNYder, A. M., STricker, E. M., \& Zigmond, M. J. (1985). Stressinduced neurological impairments in an animal model of Parkinsonism. Annals of Neurology, 18, 544-551.

Spirduso, W. W., Gilliam, P. E., Schallert, T., UfChurCh, M., VAUGHN, D. M., \& WILCOX, R. E. (1985). Reactive capacity: A sensitive behavioral marker of movement initiation and nigrostriatal dopamine function. Brain Research, 335, 45-54.

Strllar, J. R., Waraczynsk, M., \& BrUNo, J. P. (1988). Neonatal dopamine depletions spare lateral hypothalamic stimulation reward in adult rats. Pharmacology, Biochemistry \& Behavior, 30, 365-370.

TAKEICHI, T., KurumiYA, S., Umemoto, M., \& OlDS, M. E. (1986). Roles of catecholamine terminals and intrinsic neurons of the ventral tegmentum in self-stimulation investigated in neonatally dopaminedepleted rats. Pharmacology, Biochemistry \& Behavior, 24, 1101-1109.

Teitelbaum, P., Schallert, T., \& Wishaw, I. Q. (1983). Sources of spontaneity in motivated behavior. In E. Satinoff \& P. Teitelbaum (Eds.), Handbook of behavioral neurobiology (Vol. 6, pp. 23-65). New York: Plenum.

Teitelbaum, P., Wolgin, D. L., DeRyck, M., Marin, O. S. M. (1976). Bandage-backfall reaction: Occurs in infancy, hypothalamic damage, and catalepsy. Proceedings of the National Academy of Sciences of the United States of America, 73, 3311-3314.

UNGERSTEDT, U. (1971). Adipsia and aphagia after 6-hydroxydopamine 
induced degeneration of the nigro-striatal dopamine system. Acta Physiologica Scandinavica, 82(Suppl. 367), 96-122.

VANDERWOLF, C. H., KolB, B., \& CoOLEY, R. K. (1978). Behavior of the rat after removal of the neocortex and hippocampal formation. Journal of Comparative \& Physiological Psychology, 92, 156-175.

VAN HARREveld, A., \& Bogen, J. E. (1961). The clinging position of the bulbocapninized cat. Experimental Neurology, 4, 241-261.

Weihmuller, F. B., \& BRuno, J. P. (1989). Drinking behavior and motor function in rat pups depleted of brain dopamine during development. Developmental Psychobiology, 22, 101-113.

Whishaw, I. Q., \& DuNNETT, S. B. (1985). Dopamine depletion, stimulation or blockade in the rat disrupts spatial navigation and locomotion dependent upon beacon or distal cues. Behavioural Brain Research, 18, 11-29.

WhishaW, I. Q., Funk, D. R., HaWryluk, S. J., \& KarbasheWSKI, E. D. (1987). Absence of sparing of spatial navigation, skilled forelimb and tongue use and limb posture in the rat after neonatal dopamine depletion. Physiology \& Behavior, 40, 247-253.

Whishaw, I. Q., \& KoLB, B. (1983). "Stick out your tongue": Tongue protrusion in neocortex and hypothalamic damaged rats. Physiology \& Behavior, 30, 471-480.

Whishaw, I. Q., Nonneman, A. J., \& Kol8, B. (1981). Environmental constraints on motor abilities used in grooming, swimming, and eating by decorticate rats. Journal of Comparative \& Physiological Psychology, 95, 792-804.
WhishaW, I. Q., O'ConNoR, W. T., \& DUNnETT, S. B. (1986). The contributions of motor cortex, nigrostriatal dopamine and caudateputamen to skilled forelimb use in the rat. Brain, 109, 805-843.

Whishaw, I. Q., Robinson, T. E., Schallert, T., DeRYCK, M., \& RAMIREZ, V. D. (1978). Electrical activity of the hippocampus and neocortex in rats depleted of brain dopamine and norepinephrine: Relations to behavior and effect of atropine. Experimental Neurology, 62, 748-767.

Whishaw, I. Q., Schallert, T., \&olb, B. (1981). An analysis of feeding and sensorimotor abilities of rats after decortication. Journal of Comparative \& Physiological Psychology, 95, 85-103.

WhrTe, N. M. (1986). Control of sensorimotor function by dopaminergic nigrostriatal neurons: Influence on eating and drinking. Neuroscience \& Biobehavioral Reviews, 10, 15-36.

Zhou, F. C., \& MURPHY, J. M. (1989). A serotonergic neurotrophic factor is induced in striatum by lesioning dopamine neurons in substantia nigra of adult rat. Society for Neuroscience Abstract, 15, 1363.

Zigmond, M. J., \& STRICKER, E. M. (1973). Recovery of feeding and drinking by rats after intraventricular 6-hydroxydopamine or lateral hypothalamic lesions. Science, 182, 717-720.

(Manuscript received June 6, 1988; revision accepted for publication June 8, 1989.) 